Original Research Article

\title{
Drug utilization study in outpatient ophthalmology department of government medical college, Nellore, India
}

\author{
Naveen Choudary Gorantla, Lalitha Hanumanthu*
}

Department of Pharmacology, ACSRGMC, Dr. NTRUHS,

Nellore, Andhra Pradesh, India

Received: 19 March 2018

Revised: 23 March 2018

Accepted: 26 March 2018

*Correspondence to:

Dr. Lalitha Hanumanthu,

Email: drlalithah@gmail.com

Copyright: (C) the author(s), publisher and licensee Medip Academy. This is an openaccess article distributed under the terms of the Creative Commons Attribution NonCommercial License, which permits unrestricted noncommercial use, distribution, and reproduction in any medium, provided the original work is properly cited.

\begin{abstract}
Background: Drug utilization studies are an important part of rational use of drugs. This study was planned to assess drug utilization pattern in Ophthalmology outpatient department.

Methods: After approval from Ethics Committee, 620 prescriptions were analyzed according to WHO drug indicators.

Results: 2.4 drugs were prescribed on an average per prescription. Antibiotics $(49 \%)$ were the most commonly used drugs. Fluoroquinolones (54\%) were frequently used. Topical route was preferred route of drug administration. Prescription of generic drugs was not optimal (13\%). Duration of therapy was missing in many prescriptions.

Conclusions: Generic prescribing can be improved. Duration of therapy should be mentioned in all prescriptions.
\end{abstract}

Keywords: Drug utilization, Generics, Ophthalmology, Outpatients, Prescriptions

\section{INTRODUCTION}

Definition of drug utilization work adopted by World Health Organization (WHO): studies of "the marketing, distribution, prescription, and use of drugs in a society, with special emphasis on the resulting medical, social, and economic consequences". ${ }^{1}$

Marketing of new drugs, variations in the pattern of drug prescribing, concerns about the delayed adverse effects of drugs and the increase in the cost of drugs has increased the importance of drug utilization studies. ${ }^{2}$ Drug utilization studies are powerful exploratory tools to ascertain the role of drugs in the society. ${ }^{3}$ The discipline of drug utilization research is closely related and linked mainly to the broader field of pharmacoepidemiology, but also to health outcomes research, pharmacovigilance and health economics. ${ }^{4}$

Drug utilization research will often point to and profile the discrepancy that persists between true need and therapeutic practice, and perhaps serve as a tool in correcting it. ${ }^{5}$

The efficacy and safety of drugs used in ophthalmology is often confounded by the accuracy of dose administration of the ophthalmic preparation by the patients which in turn is dependent on proper education by the Ophthalmologist, a rational prescription and proper comprehension of the information provided to the patient, besides many other factors. ${ }^{6}$ 
Topical ophthalmic Non-Steroidal Anti-Inflammatory Drugs (NSAIDs) can not only produce local irritant effects of conjunctival hyperaemia, burning, stinging and corneal anaesthesia but also have association with serious complication like indolent corneal ulceration and fullthickness corneal melts. ${ }^{7}$

Antibiotics are widely prescribed for various ophthalmic diseases. The repeated use of ophthalmic antibiotics selects for resistant strains. ${ }^{8}$ Drugs themselves are not as bad as the way in which we use them; a therapeutic audit is required at all levels of the therapeutic chain to ensure safe and effective medical care. ${ }^{9}$

Therefore, the present study was undertaken with the aim to investigate drug utilization and prescribing practices of ophthalmologists with emphasis on antimicrobial utilization in a tertiary care teaching hospital in Nellore.

\section{METHODS}

This study was carried out in Outpatient Ophthalmology Department of ACSR Government Medical College, Nellore between July 2017 and October 2017. Permission was obtained from the Institutional Ethics Committee. This was an open label, cross sectional, prospective, noninterventional, observational study conducted by Department of Pharmacology in association with Department of Ophthalmology, ACSR Government Medical College, Nellore.

\section{Inclusion criteria}

Newly registered adult patients of either sex who visited the Ophthalmology Outpatient Department with complaints like cases of red eye, discharge from eyes, itching, redness, foreign body sensation, swelling, raised intraocular pressure, and eye trauma were included.

\section{Exclusion criteria}

Cases of cataract, postoperative follow ups, any diagnostic test/procedure, and repeated follow-up cases were excluded from the study.

Data was collected prospectively from the out-patients unit of the ophthalmology Department between 9 AM and 12 PM, twice a week (Monday and Tuesday) for a period of 4 months.

Prescriptions from each patient are taken into consideration for this study and only those medications used for treating ocular disorders were considered. All drugs prescribed were noted including dose, route, dosage form, frequency of administration, indications for prescription and duration of therapy, numbers of drugs prescribed from Essential Drug list were also noted as per WHO/International Network of Rational Use of Drugs (INRUD) drug use indicators. ${ }^{10}$
Essential medicines as defined by the WHO are those drugs that satisfy the health-care needs of the majority of the population; they should therefore be available at all times in adequate amounts and in appropriate dosage forms, at a price the community can afford. ${ }^{11}$ Central Drugs Standard Control Organization, the regulatory body in India, has recently formulated the National list of essential medicines in 2015.

A total of 620 prescriptions were analyzed following WHO recommendation. ${ }^{10}$ that the study of a single health facility should measure facility specific prescribing indicators with a $95 \%$ confidence limit plus minus $10 \%$. Accordingly, it has been recommended that at least 600 encounters or more should be included in a cross-sectional survey. Data was coded and entered with the help of a statistician to minimize the data entry errors. Data analyzed on EPI INFO version 3.5.4 and MS EXCEL. The different variables were expressed as frequencies and percentages. Chi square test was used as a test of significance $(\mathrm{P}<0.05)$

\section{RESULTS}

A total of 620 prescriptions were analyzed. The total number of drugs in these prescriptions was 1488 . The number of drugs per prescription varied from one to five, with an average of 2.4 per prescription. Majority prescriptions had 2 drugs as seen in Figure 1.

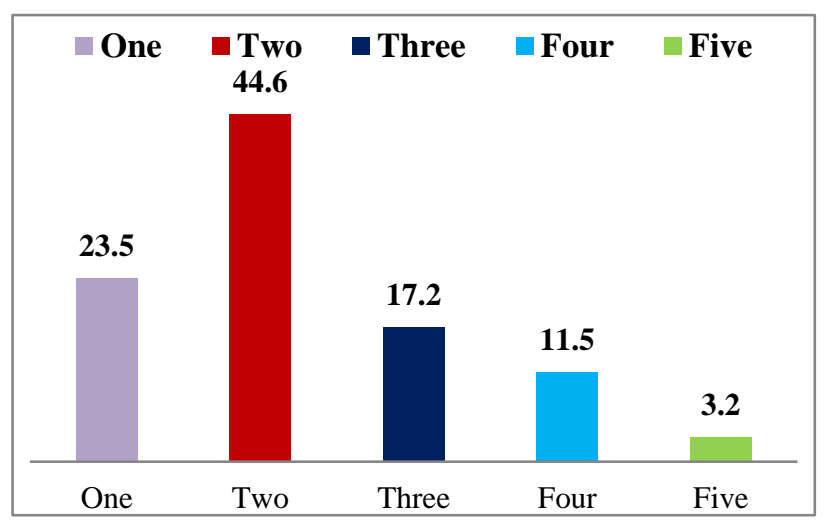

Figure 1: The number of drugs per prescription.

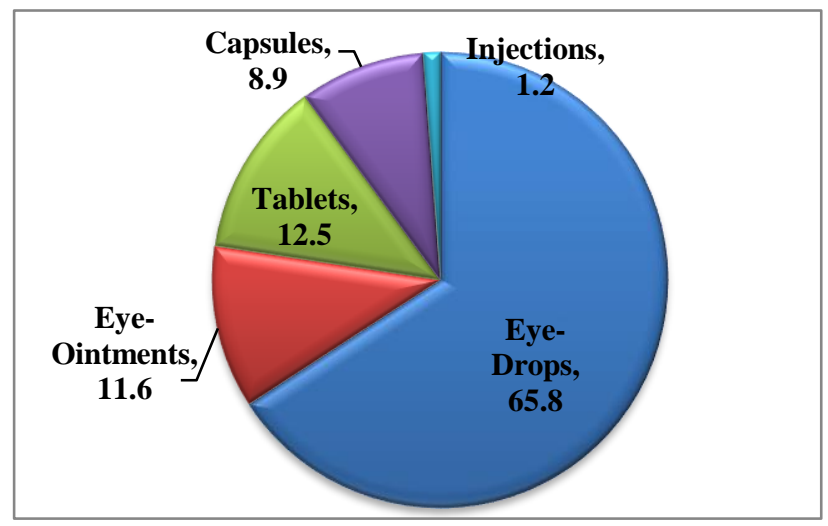

Figure 2: The various dosage forms used. 
Drugs were prescribed in five different dosage forms. Eye drops were the most commonly used dosage form $65.8 \%$ followed by tablets $(12.5 \%)$, ointments $(11.6 \%)$, and capsules $(8.9 \%)$ as seen in Figure 2. Injections contributed to $1.2 \%$ of all the dosage forms prescribed as seen in Figure 2.

Study also revealed that $187(12.6 \%)$ drugs were prescribed by generic name and $1301(87.4 \%)$ drugs were prescribed by brand name as seen from Figure 3.

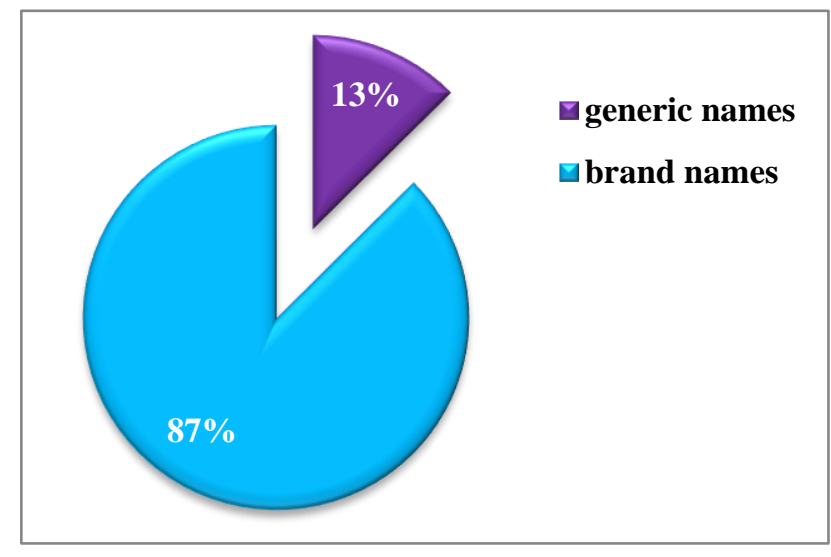

Figure 3: Prescription by generic and brand names.

The percentage of drugs prescribed from essential drug list was $45 \%(670 / 1488)$ from National List of Essential Medicines, 2015 as seen from Table 1.

Table 1: Drug utilization based indicators.

\begin{tabular}{|ll|}
\hline Indicators assessed & Data value \\
\hline $\begin{array}{l}\text { Average number of drugs per } \\
\text { prescription }\end{array}$ & 2.4 \\
\hline $\begin{array}{l}\text { Percentage of drugs prescribed by } \\
\text { generic name }\end{array}$ & $12.6 \%$ \\
\hline $\begin{array}{l}\text { Percentage of prescriptions with } \\
\text { antibiotics prescribed }\end{array}$ & $46.8 \%$ \\
\hline $\begin{array}{l}\text { Percentage of prescriptions with } \\
\text { injections prescribed }\end{array}$ & $1.2 \%$ \\
\hline $\begin{array}{l}\text { Percentage of drugs prescribed from } \\
\text { National essential medicines list }\end{array}$ & $45 \%$ \\
\hline Dosage forms recorded & $98.6 \%$ \\
\hline Frequency of therapy recorded & $95.6 \%$ \\
\hline Duration of therapy recorded & $78 \%$ \\
\hline
\end{tabular}

Dosage forms of the drugs were mentioned for $98.6 \%$ of the drugs. Frequency of drug administration was mentioned for $95.6 \%$ of the prescriptions. Duration of treatment was specified for $78 \%$ of the prescribed drugs.

The number of encounters with antibiotics was 290/620 $(62.2 \%)$ which accounted for $48.6 \%$ of the total number of drugs prescribed as seen in Table2. Fluoroquinolones were the most common group of antibiotics prescribed as seen in Table 3.
Table 2: Various classes of drugs used.

\begin{tabular}{|lll|}
\hline Class of drugs & $\mathbf{N = 1 4 8 8}$ & Percentage \\
\hline Antibiotics & 723 & 48.6 \\
\hline $\begin{array}{l}\text { Anti-inflammatory and anti } \\
\text { allergic }\end{array}$ & 274 & 18.4 \\
\hline Anti glaucoma & 265 & 17.8 \\
\hline Mydriatics and cycloplegics & 118 & 7.9 \\
\hline Miotics & 68 & 4.6 \\
\hline Multivitamins & 40 & 2.7 \\
\hline
\end{tabular}

Table 3: Prescribing frequency of antibacterial classes.

\begin{tabular}{|lll|}
\hline Antibacterial class & $\begin{array}{l}\text { Number } \\
(\mathbf{7 2 3})\end{array}$ & Percentage \% \\
\hline Fluoroquinolones & 389 & 53.8 \\
\hline Penicillins & 124 & 17.2 \\
\hline Chloramphenicol & 93 & 12.8 \\
\hline Tetracyclines & 52 & 7.2 \\
\hline Polypeptides and others & 44 & 6.1 \\
\hline Aminoglycosides & 21 & 2.9 \\
\hline
\end{tabular}

\section{DISCUSSION}

The indicators of prescribing practices measure the performance of health care providers in several key dimensions related to the appropriate use of drugs. ${ }^{10} \mathrm{WHO}$ drug use indicators were used in drug utilization studies.

Of the 620 prescriptions containing 1488 drugs studied, number of drugs per prescription ranged from one to five. In this study, most commonly two drugs were noted per prescription. Average number of drugs per prescription is an important index as it tends to measure the degree of polypharmacy. ${ }^{12}$ Other hospital based studies in India reported a value of 1.49 to 3.2 drugs per prescription. ${ }^{12-17}$ It is preferable to keep the number of drugs per prescription as low as possible since higher Figureures lead to increased risk of drug interactions, adverse effects, development of bacterial resistance and increased cost to the patient. ${ }^{18}$

In this study, most of the drugs were prescribed topically, $66 \%$ in form of drops and $12 \%$ in the form of ointment. Administering the drugs topically for eye diseases minimized their adverse effects. Generic drug use in India is yet to gain widespread popularity; the economic benefits of generic drug use are however well-known and undisputed. ${ }^{19}$ Recently, regulatory authorities of different countries are advocating generic prescribing to cut total health-care cost. Similar endeavor has also been taken up by the State Government of Andhra Pradesh in promoting Anna Sanjeevani outlets that specifically sell generic drugs. In this backdrop, the percentage of drugs prescribed by generic names in this study was $12.6 \%$, which is lower than what was reported by some studies but higher than reported by others. ${ }^{12,15-17}$ Inadequate sensitization of the clinicians to generic prescribing and the frequent visit of 
the medical representatives in health facilities may be the probable cause of the under prescribing of the drugs by generic name. Banerjee. ${ }^{13}$

The percentage of drugs prescribed from the National List of Essential Medicines 2015 was $45 \%$ which is higher compared to studies conducted in India. ${ }^{12,15,20}$ The dosage form and the frequency of drug administration have been recorded in $98.6 \%$ and $95.6 \%$ of the cases respectively. In $78 \%$ of the prescriptions, the duration of therapy was noted. This study showed a need for improvement in prescription writing, as the duration of therapy was missing in $22 \%$ of the prescriptions. In this study, number of encounters with antibiotics was around $47 \%$. At $49 \%$ of the total drugs prescribed, antimicrobial agents constituted the most commonly prescribed drugs. Other similar studies in ophthalmology in India have reported 30\%-45\% encounters with antibiotics lower than our study. ${ }^{14,17}$ Fluoroquinolones were the most common group of antibiotics prescribed which were similar to reports of previous studies done in ophthalmology. ${ }^{13,14,17}$ Ciprofloxacin $0.3 \%$ as drops and ointment is included in National List of Essential Medicines 2015, deemed to be available at Primary, Seconday and Tertiary levels of health care and hence preferred in many prescriptions as patients could use them free of cost. $^{20}$ Newer fluoroquinolones like Moxifloxacin were prescribed in severe cases.

The prescribing pattern observed in the current study was in accordance with the accepted norms of treatment of ocular diseases, The present study revealed certain lacunae in the prescribing practices of the Ophthalmologists in this institute evident by the low generic prescribing, inadequate information about duration of therapy in many prescriptions. There is margin for betterment. Ophthalmologists should be encouraged to prescribe by generic name and opt for essential drugs from National List of Essential Medicines. The study suggests educational initiative, development of drug policy, and National Essential drug list based hospital formulary to reduce the drug cost and ensure rational use of medicines.

\section{ACKNOWLEDGEMENTS}

Authors would like to thank their Professor and Head of Department of Pharmacology, Dr. V.L.M. Raman for his valuable guidance.

\section{Funding: No funding sources}

Conflict of interest: None declared

Ethical approval: The study was approved by the Institutional Ethics Committee of ACSR GMC, Nellore, India

\section{REFERENCES}

1. WHO Expert Committee. The Selection of Essential Drugs, technical Report Series no.615. Geneva: World Health Organization, 1977. Available at: http://apps.who.int/medicinedocs/documents/s20185e n/s20185en.pdf

2. Hasmnis AA, Patil SS, Narayan KA, Rashid AK, Mohanty BK. Drug utilization study for acute illnesses in village Banggol, Malaysia; The findings of a household survey. Al Ameen J Med Sci. 2010;3(2):165-8.

3. Shalini S, Ravichandran V, Mohanty BK, Dhanraj SK, Saraswathi R. Drug Utilization Studies -An overview. International Journal OF Pharmaceutical Sciences and Technology. 2010;3(1).

4. Elseviers M, Björn W, Anna BA, Morten A, Benko R, Marion B, et al. Drug Utilization Research: Methods and Applications. Available at: https://www.pharmacoepi.org/pub/?id=153e8171b20d-fd59-6110-4da24d84caaf

5. Dukes MNG. WHO Regional Publications European Series; No. 45. Drug utilization studies: methods and uses. $\quad \mathrm{Pg} \quad 36 . \quad$ Available at: http://apps.who.int/medicinedocs/documents/s21868e n/s21868en.pdf

6. Tsai T, Robin AL, Smith III JP. An Evaluation of How Glaucoma Patients Use Topical Medications: A Pilot Study. Transactions of the American Ophthalmological Society. 2007;105:29-35.

7. Gaynes BI, Fiscella R. Topical nonsteroidal antiinflammatory drugs for ophthalmic use: a safety review. Drug Saf. 2002;25(4):233-50.

8. Kim SJ, Toma HS. Antimicrobial Resistance and Ophthalmic Antibiotics1-Year Results of a Longitudinal Controlled Study of Patients Undergoing Intravitreal Injections. Arch Ophthalmol. 2011;129(9):1180-8.

9. Krishnaswamy K, Kumar DB, Radhaiah G. A drug survey- precepts and practices. European Journal of Clinical Pharmacology. 1985;29(3):363-70.

10. World Health Organization (WHO) and International Network for Rational Use of Drugs, How to Investigate Drug Use in Health Facilities: Selected Drug Use indicators, WHO/DAP/93.1, WHO, Geneva, Switzerland, 1993.

11. The Selection and Use of Essential Medicines-WHO Technical Report Series, No. 914, 2003. Available at: http://www.apps.who.int/medicinedocs/en/d/Js4875e/ 5.2.html

12. Jadhav PR, Moghe VV, Yeshwant A. Deshmukh Drug Utilization Study in Ophthalmology Outpatients at a Tertiary Care Teaching Hospital Hindawi Publishing Corporation ISRN Pharmacology. 2013:5. Article ID 768792.

13. Banerjee I, Bhadury T, Sengupta T, Roy D. Drug Utilization Study in Ophthalmology Out patient Department of a Medical College in India Annals of Medical and Health Sciences Research | Jul-Aug 2014;4(4).

14. Maniyar Y, Bhaxivitamath P, Akkone V. A Drug Utilization Study In The Ophthalmology Department Of a Medical College, Karnataka, India Journal of Clinical and Diagnostic Research. 2011;5(1):82-4. 
15. Dhali D, Halder U, Santra RD, Biswas M. Drug Utilization Study in Outpatient Ophthalmology Department of A Tertiary Care Hospital In West Bengal. Indian Journal of Medical Research and Pharmaceutical Sciences. 2016;3(6).

16. Nehru M, Kohli K, Kapoor B, Sadhotra P, Chopra V, Sharma R. Drug Utilization Study in Outpatient Ophthalmology. Department of Government Medical College Jammu. JK Science. 2005;7(3).

17. Vaniya HV, Darji NH, Patel VR, Gohel DJ. Drug Utilization Study in Ophthalmology Outpatients in a Tertiary Care Hospital. Advances in Pharmacology and Pharmacy. 2016 Jun;4(2):11-5.

18. Sharma D, Reeta KH, Badyal DK, Garg SK, Bhargava VK. Antimicrobial prescribing pattern in an Indian tertiary hospital. Indian journal of physiology and pharmacology. 1998 Oct;42(4):533-7.
19. Das M, Choudhury S, Maity S, Hazra A, Pradhan T, Pal A, Roy RK. Generic versus branded medicines: An observational study among patients with chronic diseases attending a public hospital outpatient department. Journal of natural science, biology, and medicine. 2017 Jan;8(1):26.

20. National List of Essential Medicines (NLEM); 2015:60. Available at: http://apps.who.int/medicinedocs/documents/s23088e n/s23088en.pdf

Cite this article as: Gorantla NC, Hanumanthu L. Drug utilization study in outpatient ophthalmology department of government medical college, Nellore, India. Int J Basic Clin Pharmacol 2018;7:844-8. 